УДК 330.342

DOI 10.18101/2304-4446-2021-1-3-9

\title{
ЭВОЛЮЦИЯ ФЕНОМЕНА «ЦИФРОВАЯ ЭКОНОМИКА»
}

\author{
(C) Аверина Ирина Сергеевна \\ кандидат экономических наук, доцент, \\ Волгоградский государственный университет \\ Россия, 400062, г. Волгоград, пр-т Университетский, 100 \\ averinaIS@volsu.ru
}

\begin{abstract}
Аннотация. Статья представляет собой исследование эволюции понятия «цифровая экономика», базирующееся на изучении характеристик рассматриваемого феномена с точки зрения отечественных и зарубежных ученых. Автором предпринята попытка проведения системного анализа развития указанного термина и его систематизации на основе выделения этапов в соответствии с различными методологическими подходами (факторным, структурным, системным, институциональным). На основе комплексного анализа осуществлено выявление общих и специфических системных характеристик указанного явления (порождаемых различными условиями при ее формировании на всех уровнях функционирования экономики), факторов, стимулирующих развитие процессов цифровизации или сдерживающих его, а также определены границы распространения информационно-коммуникационных технологий в хозяйственной системе в целом. Детальное изучение теоретических аспектов рассматриваемого объекта должно послужить основой для дальнейших разработок практического характера.

Ключевые слова: цифровая экономика; промышленная революция 4.0; парадигма экономического развития; экономическое развитие; государственные программы; хозяйственная система; глобальная трансформация; смена парадигмы развития; цифровизация.
\end{abstract}

\section{Для цитирования}

Аверина И. С. Эволюция феномена «цифровая экономика» // Вестник Бурятского государственного университета. Экономика и менеджмент. 2021. № 1. С. 3-9.

Современные реалии ставят перед обществом множество задач, при этом одной из ключевых является адаптация хозяйственных систем к новым условиям, формируемым в процессе цифровизации экономического пространства, обусловленного феноменом новой технологической революции, которая получила название - Industry 4.0 (промышленная революция 4.0). Подобные изменения порождают фундаментальные трансформации в жизнедеятельности человечества, базисом которых послужат кардинальные перемены во всех отраслях народного хозяйства, вызванные технологическими прорывами в самом широком спектре областей. Цифровизация экономики является одним из основных компонентов указанного явления [14].

Следует отметить, что доля цифровой экономики ежегодно растет в развивающихся странах на 15-25\% [8], а следовательно, поиск оптимальных мер по 
адаптации хозяйственных систем к процессам цифровизации является важным направлением научных исследований как в России, так и за рубежом.

Современное понимание термина «цифровая экономика» вошло в научный оборот в 1995 г. благодаря изысканиям американского ученого Н. Негропонте [7], который в первую очередь связал его с развитием информационнокоммуникационных технологий (ИКТ). Данное представление скорее отражает общее восприятие влияния ИКТ на цифровизацию хозяйственной жизни общества и указывает на технологический фактор как на главный детерминант, определивший появление исследуемого феномена.

Дальнейшее распространение рассматриваемого термина можно проследить в трудах канадского ученого-исследователя Д. Тампскота [15], охарактеризовавшего изменения, происходящие в хозяйственной жизни людей, с позиции термина «цифровое общество». Также Н. Лэйном «цифровая экономика» рассматривается как система, порождающая указанные изменения в организации торговли и способствующая развитию ее электронной составляющей [5].

В этот же период Л. Марджхерио уточняет структурные компоненты исследуемого явления (расширение сети Интернет; цифровая доставка товаров; электронная торговля; розничная продажа физических товаров) [3]. Также структура цифровой экономики была проанализирована Р. Клингом и Р. Лэмбом, выделившими среди элементного состава следующие части: смешанные цифровые продукты; продукты, предоставляемые посредством цифровых технологий; ITиндустрию [4]. Указанные взгляды на структурные элементы отнюдь не носят противоречивого характера, а лишь указывают, что авторы используют при исследовании различные критериальные признаки. Данное обстоятельство указывает на многоаспектность термина «цифровая экономика».

С другого ракурса рассматривают цифровую экономику Е. Бринольфсон и Б. Кахин, говоря о ней как о движущей силе, способствующей росту экономики [2]. Данный подход также указывает на факторную составляющую, однако влияние прослеживается взаимообратное. Взгляды Д. Тампскота, Н. Лэйна, Р. Клинга и Р. Лэмба сосредоточены на влиянии ИКТ на развитие цифровой экономики, а исследование Е. Бринольфсона и Б. Кахина рассматривает ее саму как фактор, способствующий экономическому росту. Исследуя структурную составляющую цифровой экономики, следует выделить ее элементы, обозначенные Т. Месенбургом, разделившим ее на три составные части: инфраструктуру электронного бизнеса, электронный бизнес и электронную коммерцию [6].

Масштаб развития цифровых технологий и внедрение их в хозяйственную жизнь общества также отмечаются учеными Глобального института McKinsey, указывающими на радикальность и значимость изменений, которые повлечет за собой цифровизация [1]. Данное понимание сущности явлений, порождаемых промышленной революцией 4.0, хотя и носит самый обобщенный характер, однако позволяет обозначить свойство масштабности перемен, происходящих в социально-экономической и других сферах. Наиболее общее отражение термин «цифровая экономика» получил в авторской интерпретации отечественных ученых Е. А. Устюжаниной, А. В. Сигарева и Р. А. Шеина.

Цифровая экономика - это «объективно обусловленный процесс, затрагивающий в той или иной мере экономики практически всех развитых и развиваю- 
щихся стран» [13]. Развитие общества обусловило процесс эволюции хозяйственных систем не только на макроэкономическом и микроэкономическом уровне, но и в глобальном масштабе.

Данное обстоятельство явилось основой для создания различных стратегических государственных программ, осуществляемых в рамках экономической политики большинства мировых держав. В качестве примера следует привести следующие программы: Digital Economy (США), Internet Economy (Китай), Industrie 4.0 (Германия), «Цифровая экономика» (Россия) [13] и другие.

Процессный подход к исследованию термина «цифровая экономика» не является единственным. Рассмотрим более подробно указанный феномен с различных точек зрения отечественных и зарубежных авторов. Цифровая экономика может рассматриваться как подсистема, как электронный механизм функционирования и развития системной экономики [11], а также представлять собой модель, отражающую экономические отношения в рамках процесс воспроизводства на основе информационно-коммуникационных технологий. Дополняя вышеуказанную концепцию представления цифровой экономики как подсистемы, целесообразно привести мнение Р. Бухта и Р. Хикса, которые под анализируемым феноменом рассматривают часть экономики, представленную компаниями, работающими в рамках бизнес-модели, основанной на цифровых продуктах или услугах. При этом сам процесс производства таких товаров связан с цифровыми технологиями [8]. Данный подход говорит об анализе процессов цифровизации и их влиянии на микроэкономический уровень хозяйствования.

В докладе Всемирного банка приводится несколько иное определение исследуемого понятия и поясняется, что «цифровая экономика» - это система социальноэкономических и культурных отношений, основанных на использовании инфокоммуникационных технологий [10]. Данное определение указывает на системное восприятие исследуемого феномена, однако более целесообразным было бы обозначить обобщенно и представить всю совокупность отношений как хозяйственные, возникающие и трансформирующиеся в процессе развития общества.

В отечественной науке благодаря изысканиям Т. Н. Юдиной исследуются границы цифровой экономики: игнорирование нравственных принципов, запрет криптовалюты в ряде стран, проблема монопольного владения информацией и получения сверхприбыли, усиление возможности совершения экономических преступлений [16]. Указанные аспекты ограничивают функционирование экономической системы в рамках ее цифровизации. Однако подобные ограничения носят скорее положительный характер, так как посредством институциональных барьеров создаются возможности нивелирования отрицательных последствий внедрения информационно-коммуникационных технологий во все сферы жизни общества.

Добавляя институциональное содержание к рассмотренным выше аспектам, необходимо отметить, что трансформации, происходящие в хозяйственной системе любого уровня (в данном случае обусловленных цифровизацией), порождаются или требуют соответствующих изменений «правил игры»в обществе [12], что и указывает на рациональность создания отмеченных выше «ограничителей» данного процесса. 
Указанные выше различные подходы и эволюция взглядов научного сообщества на определение термина «цифровая экономика» целесообразно представить в виде таблицы:

Таблица 1

Эволюция подходов к определению термина «цифровая экономика»

\begin{tabular}{|c|c|c|c|}
\hline Авторы & Подход & Сущностные аспекты определения & Год \\
\hline Н. Негропонте & $\begin{array}{l}\text { факторный } \\
\text { анализ }\end{array}$ & $\begin{array}{l}\text { цифровая экономика в контексте развития } \\
\text { информационно-коммуникационных техно- } \\
\text { логий }\end{array}$ & 1995 \\
\hline Д. Тампскот & $\begin{array}{l}\text { факторный } \\
\text { анализ }\end{array}$ & $\begin{array}{l}\text { трансформационная природа цифровой } \\
\text { экономики и ее влияние на общество }\end{array}$ & 1999 \\
\hline Н. Лэйн & $\begin{array}{l}\text { системный } \\
\text { анализ }\end{array}$ & $\begin{array}{l}\text { цифровая экономика, породившая измене- } \\
\text { ния в организации торговли }\end{array}$ & 1999 \\
\hline Л. Марджхерио & $\begin{array}{l}\text { структурный } \\
\text { анализ }\end{array}$ & компоненты цифровой экономики & 1999 \\
\hline Р. Клинг, Р. Лэмб & $\begin{array}{l}\text { структурный } \\
\text { анализ }\end{array}$ & составляющие цифровой экономики & 1999 \\
\hline $\begin{array}{l}\text { Е. Бринольфсон, } \\
\text { Б. Кахин }\end{array}$ & $\begin{array}{l}\text { факторный } \\
\text { анализ }\end{array}$ & $\begin{array}{l}\text { цифровая экономика как движущую силу } \\
\text { экономического роста }\end{array}$ & 2000 \\
\hline Т. Месенбург & $\begin{array}{l}\text { структурный } \\
\text { анализ }\end{array}$ & $\begin{array}{l}\text { цифровая экономика делится на три состав- } \\
\text { ные части }\end{array}$ & 2001 \\
\hline $\begin{array}{l}\text { М. Бодэн, } \\
\text { К. Кагнин и др. }\end{array}$ & $\begin{array}{l}\text { факторный } \\
\text { анализ }\end{array}$ & $\begin{array}{l}\text { цифровая экономика указывает смену пара- } \\
\text { дигмы экономического развития }\end{array}$ & 2010 \\
\hline Т. Н. Юдина & $\begin{array}{l}\text { системный } \\
\text { анализ }\end{array}$ & $\begin{array}{l}\text { рассмотрения ограничений функциониро- } \\
\text { вания системы }\end{array}$ & 2016 \\
\hline М. Роуз & $\begin{array}{l}\text { системный } \\
\text { анализ }\end{array}$ & $\begin{array}{l}\text { цифровая экономика - это система, состо- } \\
\text { ящая из информации и информационно- } \\
\text { коммуникационных технологий }\end{array}$ & 2016 \\
\hline $\begin{array}{l}\text { Е. В. Устюжанина, } \\
\text { А. В. Сигарев, } \\
\text { Р. А. Шеин }\end{array}$ & $\begin{array}{l}\text { системный } \\
\text { анализ }\end{array}$ & $\begin{array}{l}\text { цифровая экономика как технологическая } \\
\text { система }\end{array}$ & 2017 \\
\hline Л. Д. Капранова & $\begin{array}{l}\text { системный } \\
\text { подход }\end{array}$ & $\begin{array}{l}\text { цифровая экономика как система социаль- } \\
\text { но-экономических отношений }\end{array}$ & 2018 \\
\hline $\begin{array}{l}\text { М. В. Косолапо- } \\
\text { ва и др. }\end{array}$ & $\begin{array}{l}\text { системный } \\
\text { подход }\end{array}$ & $\begin{array}{l}\text { цифровая экономика как подсистема } \\
\text { народного хозяйства, которая помогает ее } \\
\text { функционированию }\end{array}$ & 2018 \\
\hline Р. Бухт, Р. Хикс & $\begin{array}{l}\text { системный и } \\
\text { процессный } \\
\text { подходы }\end{array}$ & $\begin{array}{l}\text { цифровая экономика как подсистема, про- } \\
\text { изводство в которой основано на цифровых } \\
\text { технологиях }\end{array}$ & 2018 \\
\hline
\end{tabular}

Источник: составлено автором

Из таблицы 1 следует, что эволюцию термина «цифровая экономика» можно условно разделить на три этапа:

- I этап (1995-2000) — этап зарождения современного понимания термина «цифровая экономика» в основном характеризуется его восприятием как явле- 
ния, обусловленного влиянием некого фактора - информационнокоммуникационных технологий;

- II этап (2001-2015) - этап становления термина «цифровая экономика» взаимосвязан с попыткой выявления и анализа его структурных элементов, а также их определения функциональной направленности;

- III этап (2016 г. по наст. вр.) - этап дальнейшего развития термина «цифровая экономика» представляет собой попытку комплексного изучения данного феномена с позиции системного анализа, который позволяет не только детально исследовать элементную составляющую, но и выявить взаимосвязи между ними, взаимовлияние их друг на друга, а также факторы, препятствующие развитию процессов цифровизации хозяйственных систем или стимулирующие его.

Гипотетически рациональным является предположение о том, что дальнейшим этапом будет этап трансформации данного явления. Этот процесс потенциально связан с тем, что влияние цифровых технологий на все сферы жизни общества может проявляться не только с положительных сторон, но и вести к отрицательным последствиям. Поэтому усиление влияния информационнокоммуникационных технологий должно строго регламентироваться, чтобы не допускать или нивелировать его негативные последствия.

Подобные трансформации обязательны и сопровождают эволюцию любой экономической системы, которой и представляется цифровая экономика. Скорее всего, указанные изменения будут подробно исследованы, прежде всего, с позиции институционального подхода, который позволит не только выявить их наличие, но и обозначить необходимость появления новых институтов и институций [9] в случае нарушения функционирования системы. Обозначенные в исследовании «границы цифровой экономики» [16] уже демонстрируют необходимость и значимость институциональных изменений, а следовательно, указывают и на актуальность научных изысканий в данной области.

Таким образом, проанализировав различные трактовки термина «цифровая экономика», предлагаемые отечественными и зарубежными исследователями, целесообразно сделать вывод о том, что рассматриваемый феномен в процессе своей относительно недолгой эволюции прошел три этапа (зарождение, становление и развитие). Выделению этих этапов способствовала смена подходов к определению сущности процессов цифровизации и их влияния на хозяйственную систему в целом. Дальнейшее развитие феномена уже сопровождается необходимостью институциональных изменений, которые должны нивелировать негативные аспекты процессов цифровизации, влияющие на все сферы жизни общества.

Представленная периодизация термина «цифровая экономика» не является исчерпывающей и может быть дополнена и уточнена заинтересованными исследователями.

\section{Литература}

1. Boden M., Cagnin C., Carabias V., Haegeman K. Facing the future: time for the EU to meet global challenges // European Commission Joint Research Centre Institute for Prospective Technological Studies European Union, 2010. P. 44. URL: http://www.et2050.eu/docs/ 2010_IPTS_Facing_the_future. pdf (Date of accessed 10.11.2020). 
2. Brynjolfsson E., Kahin B. Introduction. Understanding the Digital Economy. Cambridge: MIT Press, 2000. P. 1-10.

3. The Emerging Digital Economy / L. Margherio [et al.]. Washington, DC: Department of Commerce, 1999. URL: http://www.esa.doc.gov/sites/default/files/ emergingdig_0.pdf (дата обращения: 11.11.2020). Текст : электронный.

4. Kling R. IT and Organizational Change in Digital Economies: a SocioTechnical Approach // ACM SIGCAS Computers and Society. 1999. Vol. 29, no. 3. P. 17-25.

5. Lane N. Advancing the digital economy into the $21^{\text {st }}$ century // Information Systems Frontiers. 1999. Vol. 1, No. 3. P. 317-320.

6. Mesenbourg T. L. Measuring the Digital Economy. U.S. Bureau of the Census. URL: http://www.census.gov/content/dam/Census/library/working-papers/2001/econ/digitalecon.pdf (дата обращения: 10.11.2020). Текст : электронный.

7. Negroponte N. Being Digital. N. Y.: Knopf, 1995. P.243.

8. Бухт Р., Хикс Р. Определение, концепция и измерение цифровой экономики // Вестник международных организаций. 2018, Т. 13. № 2. С. 143-172.

9. Иншаков О. В., Фролов Д. П. Эволюция институционализма в российской экономической мысли: монография: в 4 т. М.: Экономистъ, 2007. Т. 1.511 с.

10. Капранова Л. Д. Цифровая экономика в России: состояние и перспективы развития // Экономика. Налоги. Право. 2018. № 2. С. 58-69.

11. Косолапова М. В., Свободин В. А. Методологические вопросы системно-цифровой экономики: взаимосвязь системной и цифровой экономик // Мягкие измерения и вычисления. 2019. № 6. С.13-19.

12. Норт Д. Институты, институциональные изменения и функционирование экономики. М: Начала, 1997. 180 с.

13. Устюжанина Е. В., Сигарев А. В., Шеин Р. А. Цифровая экономика как новая парадигма экономического развития // Экономический анализ теория и практика. 2017. Т. 16, № 12. С. 2238-2253.

14. Шваб К. Четвертая промышленная революция. М.: Эксмо, 2016. 208 с.

15. Электронно-цифровое общество: плюсы и минусы эпохи сетевого интеллекта / Дон Тапскотт; пер. с англ. И. Дубинского; под ред. С. Писарева. М.: Рефл-бук, 1999. $403 \mathrm{c}$.

16. Юдина Т. Н. Осмысление цифровой экономики // Теоретическая экономика. 2016. № 3. C. 12-16.

Статья поступила в редакцию 15.12.2020; одобрена после рецензирования 28.01.2021; принята к публикации 29.01.2021.

\section{EVOLUTION OF THE PHENOMENON OF DIGITAL ECONOMY}

Irina S. Averina

Cand. Sci. (Econ.), A/Prof.,

Volgograd State University

100 Universitetsky Prospect, Volgograd 400062, Russia

averinais@volsu.ru

Abstract. The article studies the evolution of the concept "digital economy" based on the characteristics of this phenomenon by domestic and foreign scientists. We made an attempt to make a systematic analysis of the concept under consideration and its systematization build on identification of stages in accordance with various methodological approaches (factorial, structural, systemic, institutional). A comprehensive analysis identified general and specific systemic characteristics of this phenomenon (generated by various conditions 
during its development at all levels of the economy), factors stimulating or hindering the development of digitalization, and also the limits of information and communication technologies distribution in the economic system as a whole. A detailed study of the theoretical aspects of the concept under consideration should serve as the basis for further practical developments.

Keywords: digital economy; Industry 4.0; paradigm of economic development; economic development; government programs; economic system; global transformation; shift of development paradigm; digitalization. 